\title{
Atomic layer deposition of nitrogen doped Al phosphate coatings for Li-ion battery applications
}

\author{
Lowie Henderick, ${ }^{\dagger}$ Hamid Hamed, ${ }^{\dagger},{ }^{\uparrow}$ Felix Mattelaer, ${ }^{\dagger}$ Matthias Minjauw, ${ }^{\dagger}$ Johan \\ Meersschaut, ${ }^{\S}$ Jolien Dendooven, ${ }^{\dagger}$ Mohammadhosein Safari, $,, \uparrow, \|$ Philippe \\ Vereecken, ${ }^{\S}$ and Christophe Detavernier*,† \\ $\dagger$ †epartment of Solid State Sciences, Ghent University, Krijgslaan 281 S1, 9000 Gent, \\ Belgium \\ $\ddagger$ Uhasselt, Hasselt University,Institute for material research (IMO), 3590 Diepenbeek, \\ Belgium \\ 【Energy Ville 2, Thor park 8320, 3600 Genk, Belgium \\ §imec, Kapeldreef 75, B-3001 Heverlee, Belgium \\ |IMEC division IMOMEC, BE-3590, Belgium \\ E-mail: Christophe.Detavernier@Ugent.be
}

\begin{abstract}
In situ nitrogen doping of aluminum phosphate has been investigated in two different plasma enhanced atomic layer deposition (PE-ALD) processes. The first method consisted of the combination of trimethyl phosphate plasma (TMP*) with a nitrogen plasma and trimethyl aluminum (TMA), i.e. TMP* $-\mathrm{N}_{2}{ }^{*}-\mathrm{TMA}$. The second method replaces TMP* with a diethylphosphoramidate plasma (i.e. DEPA* - $\mathrm{N}_{2} *$ - TMA), of which the amine group could further aid nitrogen doping and/or eliminate the need for a nitrogen plasma step.
\end{abstract}


At a substrate temperature of $320^{\circ} \mathrm{C}$, the TMP*-based process showed saturated growth $(0.8 \mathrm{~nm} / \mathrm{cycle})$ of a nitrogen doped (approximately 8 at.\%) Al phosphate, while the process using DEPA* showed a similar amount of nitrogen but a significantly higher growth rate (1.4 nm/cycle). In the latter case, nitrogen doping could also be achieved without the nitrogen plasma, but this leads to a high level of carbon contamination. Both films were amorphous as-deposited, while X-ray diffraction peaks related to $\mathrm{AlPO}_{4}$ appeared after annealing in a He atmosphere. For high coating thickness $(>2 \mathrm{~nm})$, a significant increase in the Li-ion transmittance was found after nitrogen doping, although the coating has to be electrochemically activated. At lower thickness scales, such activation was not needed and nitrogen doping was found to double the effective transversal electronic conductivity. For the effective transversal ionic conductivity, no conclusive difference was found. When a lithium nickel manganese cobalt oxide (NMC) powder is coated with one ALD cycle of N-doped Al phosphate, the rate capability and the energy efficiency of the electrode improves.

\section{Introduction}

Energy storage is becoming increasingly important in our society, with Li-ion batteries (LIB) being one of the most popular devices. To this date, Li-ion batteries offer the highest energy and power density of all mature battery technologies ${ }^{1}$. However, due to the increasing demand for improved LIB's (improved cycle life, higher capacity at fast charging, etc.), this topic is still of high interest. A lot of the current issues with LIB's can be found in the positive electrode, where problems such as the dissolution of the active material and electrolyte oxidation lead to a poor capacity retention and rate capability ${ }^{2,3}$. Coatings such as $\mathrm{Al}_{2} \mathrm{O}_{3}$ have proven to decrease these parasitic reactions, enhancing the cycle life of the battery $^{\sqrt[4]{, 5}}$, but the kinetics are easily hampered by its poor ionic conductivity ${ }^{6,7,8,8}$. For this reason, alternative materials (such as $\mathrm{ZnO}^{9}, \mathrm{TiO}_{2}{ }^{10}, \mathrm{MnO}^{11}$ ) have been investigated, and the search for effective coating strategies is ongoing.

Phosphate materials have shown to be promising for various Li-ion battery (LIB) applications. Their applications vary from cathode materials (Ti phosphate $e^{\frac{16}{16}}$ Fe phosphate $e^{[17,[18}$ ) 
to protective coatings ( $\mathrm{Al}$ phosphate $\mathrm{e}^{[12 \sqrt{15}}$ ). The use of $\mathrm{Al}$ phosphate as a protective coating for LIB's has recently gained interest due to its very good thermal stability, as proven by Cho et $\mathrm{al}^{19}$. However, as it is still an insulating material it will hamper the kinetics of the battery system in a similar way as $\mathrm{Al}_{2} \mathrm{O}_{3}{ }^{6}$. Doping of $\mathrm{Al}$ phosphate could however alter the ionic and/or electronic conductivity, making this material more interesting. One dopant that is specifically interesting is nitrogen. Nitrogen doping has already proven to be beneficial for the electronic conductivity in $\mathrm{TiO}_{2}{ }^{20}$ and Li-phosphate films ${ }^{22}$, while increasing the lithium ion conductivity ${ }^{21}$ and thermal stability of the nitrogen doped Li-phosphate ${ }^{22}$.

In order to coat these materials uniformly and pinhole-free on the complex electrode powder surface, Atomic Layer Deposition (ALD) can be used. In this technique, the surface of the electrode is exposed to a series of gaseous precursors. As sequential exposure to self-limiting gas-surface reactions imposes an intrinsic surface-limited growth, ALD forms highly conformal and pinhole free layers ${ }^{23}$. The majority of ALD processes use thermal reactions, but in many cases the use of plasma-activated gas could improve the reactivity on the surface, effectively lowering the need for temperature or enabling reaction chemistries which are thermally not possible.

Recently, a Plasma Enhanced ALD (PE-ALD) process for the deposition of Al phosphate was proposed by Dobbelaere et $\mathrm{al}^{24}$. A thin film was grown using a combination of trimethyl phosphate plasma $\left(\mathrm{TMP}^{*}\right)$, oxygen plasma $\left(\mathrm{O}_{2}{ }^{*}\right)$ and trimethyl aluminum (TMA). The reaction mechanism leans on the self-limiting plasma polymerisation of the TMP molecule on the surface, essentially forming a thin phosphoric-acid like layer on the surface. Below approximately $300^{\circ} \mathrm{C}$, Dobbelaere found that this plasma polymerisation led to continuous CVD-like growth of a polymer film, without any saturation. However, above this temperature, the TMP plasma pulses saturated with increasing pulse time, forming the aforementioned layer. The growth per cycle for these processes was also found to be approximately $0.5 \mathrm{~nm} /$ cycle, i.e. 5 times higher than for typical ALD. By changing the metal precursor at the end of each cycle, the approach could be extended to titanium ${ }^{\sqrt{16}}$, vanadium ${ }^{\sqrt{25}}$, $\operatorname{zinc}^{\sqrt{26}}$, 
iron $^{17}$ and cobalt phosphate ${ }^{27}$.

Here, two strategies are investigated to deposit nitrogen doped aluminium phosphate. On the one hand, adding a nitrogen plasma to the $\mathrm{Al}$ phosphate PE-ALD process of Dobbelaere et al. could lead to nitrogen doping, while maintaining a high Growth Per Cycle (GPC). On the other hand, the use of diethylphosphoramidate (DEPA) as a phosphorus precursor (in the vapour phase) has already proven to be successful for efficient nitrogen incorporation $21,28$. Due to the similarities between DEPA and TMP (both molecules are shown in figure 1), one could expect similar effects when going from a vapour to a plasma. As DEPA also contains an amine group, a fast growing nitrogen doped phosphate could possibly be deposited without the need for an additional processing step in the form of a nitrogen plasma. In this work, these two novel strategies proposed to obtain N-doping of $\mathrm{Al}$ phosphate will be investigated. This means that, besides studying nitrogen doping of aluminium phosphate through ALD for the first time, the plasma polymerisation and potential use of DEPA for PE-ALD applications will be tested. The electrochemical effect of the nitrogen will also be studied by measuring the ionic and electronic conductivity of the most nitrogen rich phosphate layer.

\section{Experimental section}

Deposition system. A home-built high-vacuum ALD system with a base pressure of approximately $5 * 10^{-6}$ mbar was used to deposit the films, for which the reactor design is very similar to the system used in the work by Dobbelaere et al. ${ }^{[17}$ To reach this base pressure, the reactor walls were heated up to $120{ }^{\circ} \mathrm{C}$ and the chamber was pumped with a turbomolecular pump. The TMP (Sigma-Aldrich, 97\%) precursor was heated to $45^{\circ} \mathrm{C}$, while manually adjustable needle valves were installed to control the pressure of TMA (Sigma-Aldrich, $97 \%$ ), nitrogen gas and oxygen gas at a value of approximately $5 * 10^{-3}$ mbar. DEPA (Sigma-Aldrich, 98\%) was heated up to $115{ }^{\circ} \mathrm{C}$, and introduced in the reactor using argon at a pressure of $5 * 10^{-3}$ mbar as carrier gas. The plasma power was selected to be $200 \mathrm{~W}$ for nitrogen gas, TMP and DEPA, while the oxygen gas was pulsed as a $300 \mathrm{~W}$ plasma. The plasma was delivered to the sample surface using a remote ICP-RF plasma located above the sample surface. 
Material characterization. Pieces of a standard p-type $\operatorname{Si}(100)$ wafer (cut to size) were used for material characterisation. In situ spectroscopic ellipsometry was performed using a J.A. Woollam M-2000 ellipsometer, while fitting was done in the CompleteEASE software. Film thickness was measured by X-Ray Reflectivity (XRR). Both XRR and X-Ray Diffraction (XRD, in a Bragg-Brentano $\theta: \theta$ geometry) were carried out using a Bruker D8 diffractometer with $\mathrm{Cu} \mathrm{K} \alpha$ radiation. X-Ray Photoelectron spectroscopy (XPS) was performed using a Thermo Scientific Theta Probe XPS with Al K $\alpha$ radiation. Calibration of the XPS spectrum was performed by positioning the $\mathrm{C} 1 \mathrm{~s}$ position at $284.6 \mathrm{eV}$. To measure the composition in the bulk, the surface was etched with $\mathrm{Ar}^{+}$ions at an acceleration voltage of $3 \mathrm{keV}$ and a current of $2 \mu \mathrm{A}$. Elastic Recoil Detection ${ }^{29}$ (ERD) was carried out using a $8.0 \mathrm{MeV}^{35} \mathrm{Cl}^{4+}$ beam, with a sample tilt of $15^{\circ}$ and a scatter angle of $40.5^{\circ}$. The uncertainty on the atomic concentration measured with ERD is 2 at. $\%$ for majority constituents ( $>15$ at.\%), 1 at.\% for concentrations between 7 at.\% and 15 at.\%, 0.7 at.\% for concentrations below 7 at. $\%$ and 0.3 at.\% for concentrations below 3 at.\%. For hydrogen, there is an additional uncertainty yielding 2 at.\% for concentrations higher than 10 at. $\%, 1$ at. $\%$ when the concentration is between 10 at. $\%$ and 5 at. $\%$, and 0.5 at.\% for concentrations lower than 5 at.\%.

Electrochemical testing with planar electrode. Planar electrochemical test were performed in an argon filled glovebox in which the water and oxygen levels are kept below $1 \mathrm{ppm}$. A PTFE body is filled with electrolyte (1 $\mathrm{M} \mathrm{LiClO}_{4}$ in propylene carbonate (99.7\%, Sigma-Aldrich)) and clamped against the working electrode (a piece of a $\mathrm{Si}-20 \mathrm{~nm} \mathrm{SiO} \mathrm{S}_{2}-40 \mathrm{~nm}$ PVD TiN - $40 \mathrm{~nm} \mathrm{TiO}_{2}$ - coating electrode stack, cut to size, with coated side pointing towards the electrolyte). The total surface area of the working electrode that is exposed to the liquid electrolyte is $1.05 \mathrm{~cm}^{2}$. Li-strips (99.9\%, Sigma-Aldrich) were used as both counter and reference electrodes. For testing the electronic conductivity, a solution of $10 \mathrm{mM}$ ferrocene (98\%, SigmaAldrich) and $100 \mathrm{mM}$ Tetrabutylammonium perchlorate ( $\geq 98 \%$, Sigma-Aldrich) in propylene carbonate was made. Platinum wire (99.9\%, Sigma-Aldrich) was used as the counter electrode. The working electrode is a piece of a $\mathrm{Si}$ - $20 \mathrm{~nm} \mathrm{SiO}_{2}$ - $40 \mathrm{~nm}$ PVD TiN - coating electrode stack, cut to size. Measurements were carried out using both home-built ${ }^{[30}$ and a commercial (Metrohm Autolab PGSTAT702) potentiostats/galvanostats. Electrochemical testing with porous electrode. $\mathrm{Li}\left(\mathrm{Ni}_{0.6} \mathrm{Mn}_{0.2} \mathrm{Co}_{0.2}\right) \mathrm{O}_{2}$ ( $\mathrm{NMC}$, commercially available product), Carbon black (IMERYS Super C45), PVDF (SOLEF 5130-SOLVAY) and n-methyl-2-pyrrolidone 
(NMP, $\geq 99.8 \%$, LSI grade, Carl Roth $\mathrm{GmbH}$ ) were used to prepare slurries for the cathode electrode. The slurries contained $92 \mathrm{wt} \%$ of NMC622, $3.55 \mathrm{wt} \%$ of carbon black and $4.45 \mathrm{wt} \%$ of PVDF. To ensure a homogenous mixing of all the components, a sequential use of ultrasonic bath and planetary mixer was chosen. The whole mixing process took 20 minutes when three sets of 4 minutes planetary mixing were accomplished and each step followed by a 4 minutes sonication. Cathode electrodes were made by casting the slurry on the current collector (aluminum foil of $20 \mu \mathrm{m}$ thickness) using a doctor blade. Then, electrodes were dried at $80^{\circ} \mathrm{C}$ for $10 \mathrm{~h}$. After this step, electrodes were calendared, punched into $15 \mathrm{~mm}$ disks and dried thoroughly at $110^{\circ} \mathrm{C}$ under vacuum overnight. The ratio of solid to solvent in the slurry, the height of the doctor blade and the degree of calendaring were adjusted in order to obtain electrodes with desirable thicknesses and porosities. Standard 2325 coin-cells were assembled in an argon-atmosphere glove box. Lithium foil was used as the counter electrode and Celgard-2400 was used as the separator. The electrolyte was $1 \mathrm{M} \mathrm{LiPF} 6$ in ethylene carbonate:ethyl methyl carbonate $(3: 7 \mathrm{w} / \mathrm{w})$. All cells were tested using the BioLogic BSC-815 cycler. The cells were at rest for $24 \mathrm{~h}$ after assembly and then charged-discharged at C/10 for three cycles as the formation step. The rate capability and cyclability tests were performed between 3.0 $\mathrm{V}$ and $4.3 \mathrm{~V}$ vs Li at room temperature.

\section{Results and discussion}

\section{Plasma polymerisation}

Based on earlier work by Dobbelaere et al. ${ }^{24}$, it is known that TMP plasma (or TMP*, the star notation will be used from here on out to denote a plasma rather than a gas) polymerises at low substrate temperatures, leading to continuous CVD growth without saturation. This CVD growth can be illustrated by pulsing only TMP* (15 seconds exposure, 15 seconds pumping) at different substrate temperatures and monitoring the growth with in situ ellipsometry. The pulsing at each temperature was repeated several times to measure and calculate the decomposition rate, which is the growth of the film per second of plasmaactivated precursor exposure. Continuous growth is observed at low substrate temperatures, 
while at higher temperatures the continuous plasma polymerisation becomes inhibited in a self-limiting way (figure 17). It is at these high temperatures that PE-ALD of metal phosphates becomes possible.

As DEPA* has not been used before as a precursor for PE-ALD, not much is known about its polymerisation behaviour. That is why, before using it as a nitrogen containing phosporus precursor, the decomposition rate of $\mathrm{DEPA}^{*}$ at different substrate temperatures was measured. When pulsing only DEPA*, a similar trend in the decomposition rate is found with respect to TMP* (figure 1 a). Linear growth is observed when pulsing DEPA* below a thresh-
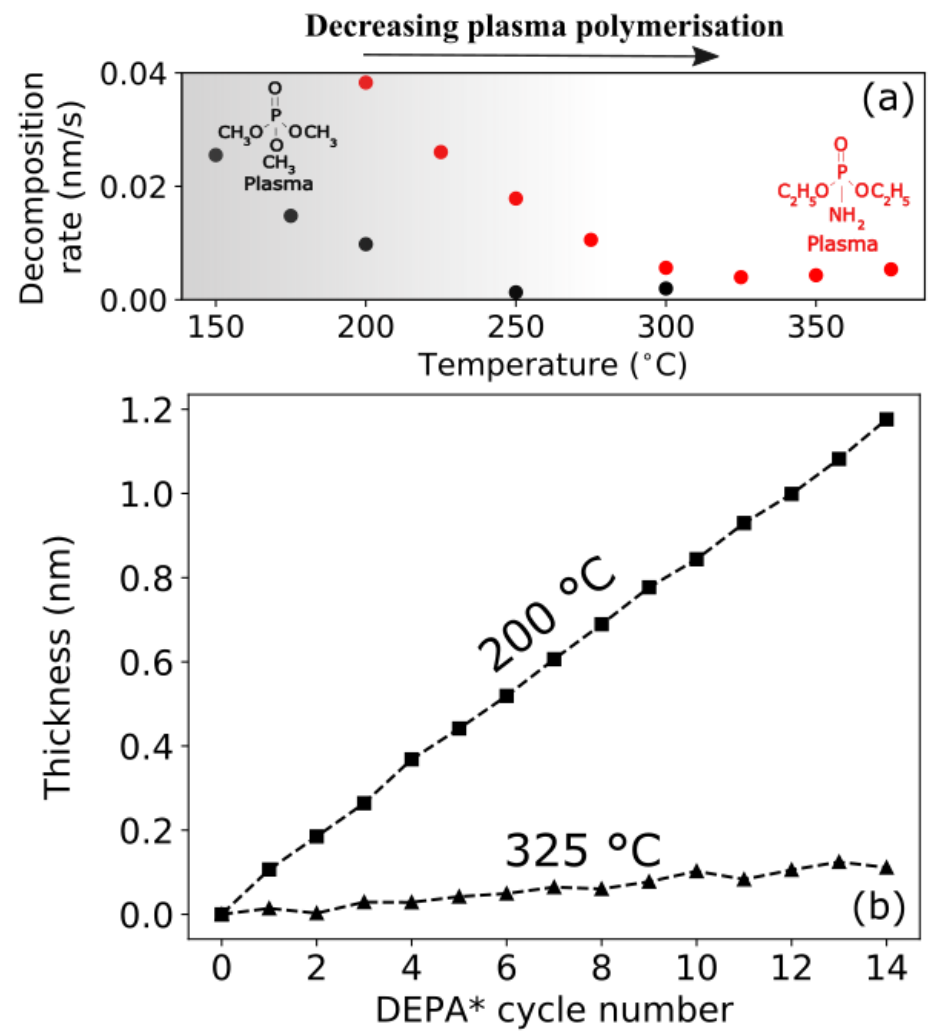

Figure 1: (a) Temperature window of respectively $\mathrm{DEPA}^{*}$ (red) and $\mathrm{TMP}^{* 24}$ (black) decomposition on a Si-surface. The decomposition rate represents the growth per second of precusor exposure. (b) The growth observed from subsequent DEPA* pulses (2 seconds per cycle) shows to be linear at low substrate temperatures, while almost no growth is observed at higher temperatures. 
old temperature, while very limited to no growth is found above this threshold (figure $1 \mathrm{~b}$ ). Due to the similarities between both molecules, a similar polymerisation effect is proposed for DEPA* (see figure S1). In the case of DEPA, This implies that $-\mathrm{C}_{2} \mathrm{H}_{5}$ bonds will partially be broken, and turned into surface reactive -OH bonds. This hypothesis is further supported by the findings of Wolf et al. ${ }^{[31}$, showing that $\mathrm{C}_{2} \mathrm{H}_{4}$ is formed when DEPA is turned into a plasma, leaving $-\mathrm{OH}$ on the molecular fragment. These phosphate esters are expected to polymerise, leading to non-saturating CVD growth.

However, as with TMP*, the decreasing trend of deposition rate with increasing substrate temperature indicates that these continuous polymerisation reactions no longer occur above a threshold temperature. Above $300^{\circ} \mathrm{C}$, both TMP and DEPA plasma species do not seem to polymerise beyond the formation of one monolayer. It is at these temperatures that PEALD using DEPA* could become possible, if the other requirements for the use as an ALD precursor (such as self-limiting chemisorption on the surface) are met.

\section{Deposition of N-doped Al phosphate}

Trimethyl phosphate. Growth of undoped phosphates has already been explored by

Dobbelaere et al. ${ }^{24}$ Using TMP as a plasma showed plasma polymerisation at low substrate temperatures, leading to a PE-CVD growth rather than ALD. However, above a threshold temperature, the plasma polymerisation is inhibited, leading to ALD growth when combining TMP* with TMA. An oxygen plasma was added after the TMP* to remove the carbon from the thin film.

The first process that is proposed to incorporate nitrogen in the phosphate, is replacing the oxygen plasma by a nitrogen plasma at a substrate temperature of $320^{\circ} \mathrm{C}$ (as the standard procedure shows saturation at this temperature). Saturation for each precursor in this altered process (which is now a sequence of TMP* $-\mathrm{N}_{2}{ }^{*}-\mathrm{TMA}$ rather than the original TMP* 


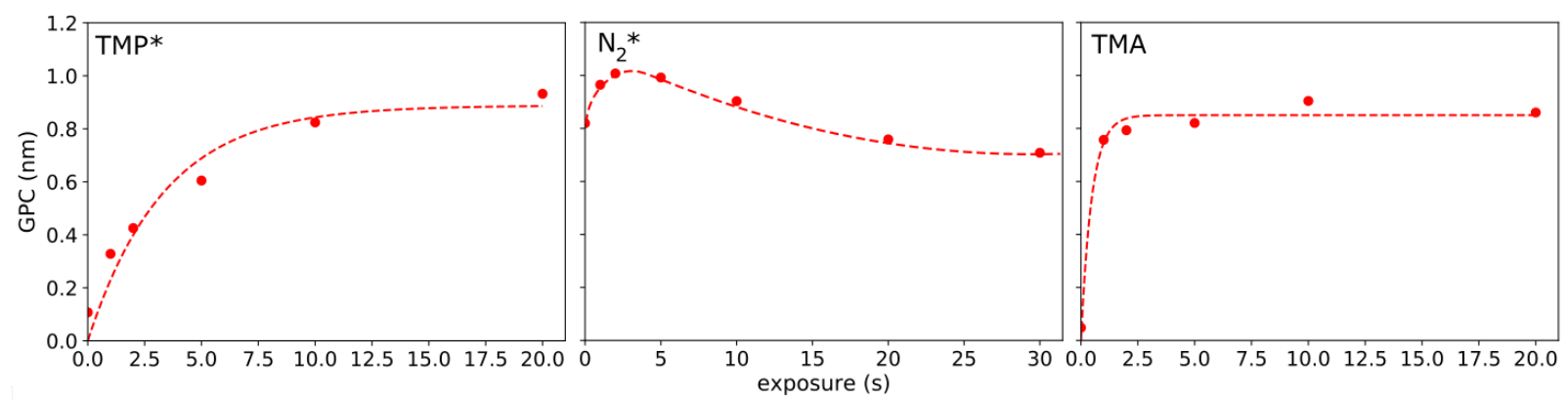

Figure 2: Growth per cycle as a function of pulse time for TMP* $\mathrm{N}_{2}{ }^{*}$ and TMA in a TMP*_ $\mathrm{N}_{2}{ }^{*}$-TMA PE-ALD process at $320^{\circ} \mathrm{C}$. The GPC values were extracted from in situ thickness measurements recorded by ellipsometry and fitted using a Cauchy model. An exponential was fitted for the saturation of TMP* and TMA, while a guide to the eye was used for $\mathrm{N}_{2}{ }^{*}$.

- $\mathrm{O}_{2}{ }^{*}$ - TMA) was then measured using in situ ellipsometry. In this test, the exposure during 2 of the 3 process steps is kept constant at 10 seconds, while the remaining exposure was varied. The saturation data is shown in figure 2 .

For TMP* and TMA, a curve of the shape $\left(1-\mathrm{e}^{-x}\right)$ was fitted, whereas the dotted line for the nitrogen plasma is a guide to the eye. All process steps saturate around $0.8 \mathrm{~nm} / \mathrm{cycle}$ at a high enough exposure. For the nitrogen plasma, it is interesting to note that an initial increase in GPC is present, after which the GPC decreases slightly and then saturates. The initial increase is thought to be activation of the surface by removal of the surface carbon groups, opening up more sites for the TMA to react with. The decrease at higher exposures could be a densification due to the incorporation of nitrogen.

Diethylphosphoramidate. In an attempt to decrease the complexity of the process, a 'dual-source' precursor containing phosphorus as well as nitrogen was introduced. If the amine group of DEPA participates in the reaction process, N-doped Al phosphate films could possibly be obtained using only two process steps, i.e. DEPA* - TMA. When performed at a substrate temperature of $325^{\circ} \mathrm{C}$, linear growth at a rate of $1.5 \mathrm{~nm} /$ cycle was found for this process (figure 3a), which is a factor 3 higher than the TMP* process. When 

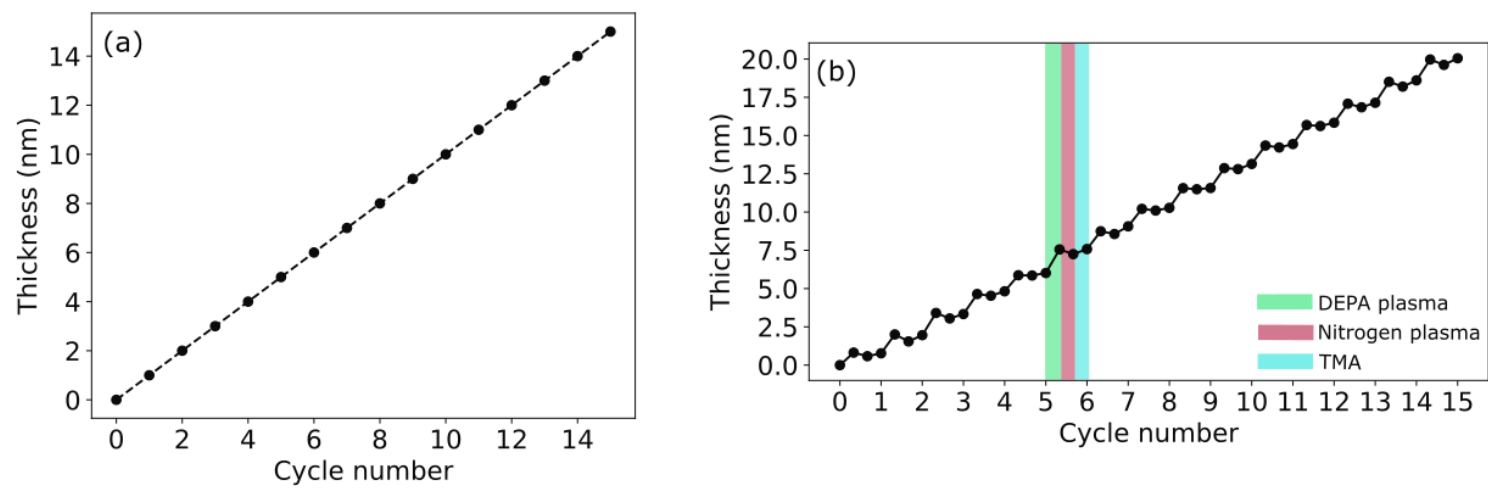

Figure 3: In situ ellipsometry of (a) the DEPA* - TMA process and (b) the DEPA* $-\mathrm{N}_{2}{ }^{*}$ TMA process in which all process contributions are studied in more detail.

the composition of these films is measured using XPS (see table 1), 3 at.\% of nitrogen was found, meaning that deposition of a nitrogen doped phosphate at a very high growth rate was obtained. Unfortunately these films also contain a high amount of carbon (originating from the relatively big ethyl group), which could be the reason for the high growth rate. As this carbon can be seen as a contaminant, the process needs to be altered in order to remove it.

As the use of an intermediate nitrogen plasma removes this carbon (table 1), the growth of the complete PE-ALD process (DEPA* $-\mathrm{N}_{2}$ * - TMA) was monitored in situ using ellipsometry after each process step. In figure $3 \mathrm{~b}$ one can observe that, when combining 30s DEPA* with $15 \mathrm{~s}_{2}{ }^{*}$ and $10 \mathrm{~s}$ TMA at a substrate temperature of $325^{\circ} \mathrm{C}$, the growth is linear. By measuring the change in thickness after every process step, one can observe that the process consists of a large increase of $1.3 \pm 0.2 \mathrm{~nm}$ due to DEPA* exposure, a small decrease of $0.2 \pm$ $0.1 \mathrm{~nm}$ due to $\mathrm{N}_{2}$ * and a small increase of $0.3 \pm 0.1 \mathrm{~nm}$ due to TMA. This leads to a growth rate of $1.4 \mathrm{~nm} /$ cycle, which is still almost three times higher than undoped $\mathrm{Al}$ phosphate and almost twice as high as the nitrogen doping process using TMP*. A possible explanation for this could be the presence of triply coordinated nitrogen in the thin film (nitrogen bound to 
three different phosphorus atoms instead of two), allowing for longer molecules to be formed on the substrate surface.

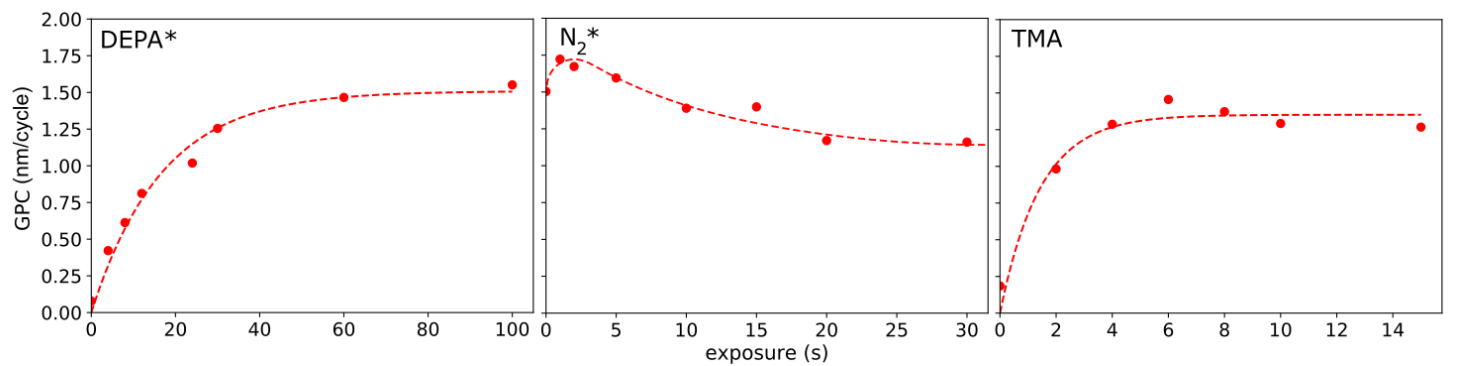

Figure 4: Growth per cycle as a function of precursor pulse time for DEPA*, $\mathrm{N}_{2}{ }^{*}$ and TMA in a DEPA*- ${ }_{2}{ }^{*}$ TMA PE-ALD process at $325^{\circ} \mathrm{C}$. The GPC values were extracted from in situ thickness measurements recorded by ellipsometry and fitted using a Cauchy model. An exponential was fitted for the saturation of $\mathrm{DEPA}^{*}$ and TMA, while a guide to the eye was used for $\mathrm{N}_{2} *$.

Similar to the process using TMP*, the saturation of each process step was tested at the temperature of $325^{\circ} \mathrm{C}$. The exposure of each precursor was fixed at $30 \mathrm{~s}, 15 \mathrm{~s}$ and $10 \mathrm{~s}$ for respectively DEPA*, $\mathrm{N}_{2}{ }^{*}$ and TMA. The results (figure 4 show saturation for both DEPA* and TMA, and an initial increase followed by a saturated decrease for $\mathrm{N}_{2}{ }^{*}$. This means that this process, with a GPC that is almost two times higher than the previous process, is a self-limited PE-ALD process.

The effect of the substrate temperature on the GPC was then investigated by combining 30s DEPA* with $15 \mathrm{~s} \mathrm{~N}_{2}^{*}$ and $10 \mathrm{~s}$ TMA in a temperature window between $200^{\circ} \mathrm{C}$ and $375^{\circ} \mathrm{C}$. In figure 5, it can be seen that the GPC follows a similar trend as only pulsing DEPA*. At the highest temperature, the GPC still decreases, which could be densification and/or evaporation of the film. At the temperature of $325^{\circ} \mathrm{C}$, There is hardly any growth solely due to the plasma polymerisation of DEPA*, as can be seen on the top figure of figure 5 . while the combination with nitrogen plasma and TMA shows growth with a high GPC of 1.4 $\mathrm{nm} /$ cycle. As saturation was already proven at this temperature, the remaining depositions 


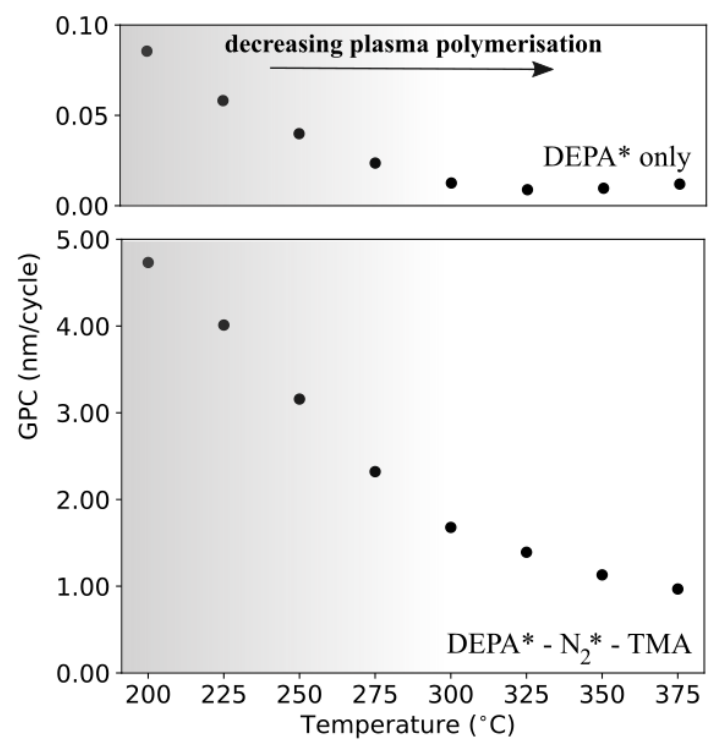

Figure 5: Temperature window of N-doped Al phosphate using DEPA* as phosphorus precursor. Top figure is the observed growth when only DEPA* is pulsed.

were performed at $325^{\circ} \mathrm{C}$.

\section{PE-ALD thin film properties}

Film composition. To determine the relative composition of the deposited film, XPS was performed. The bulk atomic concentrations for various processes can be found in table 1], in which the process of the undoped phosphate is also shown as a reference.

Besides the two novel processes as described above, several variations were examined based on adding an intermediate nitrogen plasma pulse to the oxygen plasma based processes, e.g. TMP*- ${ }_{2}{ }^{*}-\mathrm{TMA}$ to $\mathrm{TMP}^{*}-\mathrm{N}_{2}{ }^{*}-\mathrm{O}_{2}{ }^{*}-\mathrm{TMA}^{*}$ or $\mathrm{TMP}^{*}-\mathrm{O}_{2}{ }^{*}-\mathrm{N}_{2}{ }^{*}-\mathrm{TMA}$. In the case of TMP* as a phosphorous source, exposing the surface to both an intermediate oxygen plasma (for carbon removal) and a nitrogen plasma (for nitrogen incorporation) after TMP* (i.e. TMP*_ $\mathrm{O}_{2}{ }_{-}-\mathrm{N}_{2}{ }^{*}$-TMA) leads to a low amount of nitrogen in the thin film. Pulsing a nitrogen plasma after the oxygen plasma does allow for a small (but detectable, see figure S2) nitrogen peak to appear in XPS, showing that a low amount of nitrogen doping is possible. When the 
oxygen plasma is however pulsed after the nitrogen plasma $\left(\mathrm{TMP}^{*}-\mathrm{N}_{2}{ }_{-}-\mathrm{O}_{2}{ }^{*}-\mathrm{TMA}^{*}\right)$, the N 1s peak is completely removed and the final composition is very similar to the undoped phosphate process. This shows nitrogen can be incorporated, but it is easily removed by oxygen plasma. Removing the oxygen plasma from the process increases the nitrogen dopant level, while the carbon level stays low, showing that the nitrogen plasma also works as an efficient removal agent for the carbon from the TMP ligands.

Table 1: Bulk atomic concentrations of $\mathrm{N}$-doped $\mathrm{Al}$ phosphate with different intermediate plasma, measured with XPS. Concentrations labelled with '-' were below detection limit and could not be used for quantification. The error on the atomic percentage measured with XPS is estimated to be roughly $10 \%$ of the reported value.

\begin{tabular}{|c|c|c|c|c|c|}
\hline Deposition process & $\mathrm{C}($ at.\%) & $\mathrm{N}($ at.\%) & $P($ at.\%) & $\mathrm{O}($ at.\%) & Al (at.\%) \\
\hline $\mathrm{TMP}^{*} \mathrm{O}_{2}{ }^{*}-\mathrm{TMA}$ & - & - & 29.2 & 57.2 & 13.6 \\
\hline $\mathrm{TMP}^{*}{ }_{-} \mathrm{O}_{2}{ }^{*}-\mathrm{N}_{2}{ }^{*}-\mathrm{TMA}$ & - & 0.8 & 28.0 & 58.0 & 14.0 \\
\hline $\mathrm{TMP}^{*}-\mathrm{N}_{2}{ }_{-}{ }_{-} \mathrm{O}_{2}{ }_{-}-\mathrm{TMA}$ & - & - & 27.5 & 57.0 & 15.5 \\
\hline $\mathrm{TMP}^{*} \mathrm{~N}_{2}{ }^{*}-\mathrm{TMA}$ & - & 8.5 & 31.5 & 42.5 & 17.5 \\
\hline DEPA*-TMA & 18.0 & 3.0 & 30.0 & 38.0 & 11.0 \\
\hline $\mathrm{DEPA}^{*}-\mathrm{O}_{2}{ }^{*}-\mathrm{TMA}$ & - & - & 27.3 & 60.6 & 12.2 \\
\hline $\mathrm{DEPA}^{*}-\mathrm{O}_{2}{ }^{*}-\mathrm{N}_{2}{ }^{*}-\mathrm{TMA}$ & - & 2.0 & 30.0 & 53.0 & 15.0 \\
\hline $\mathrm{DEPA}^{*}-\mathrm{N}_{2}{ }^{*}-\mathrm{O}_{2}{ }^{*}-\mathrm{TMA}$ & - & - & 28.7 & 58.8 & 12.5 \\
\hline $\mathrm{DEPA}^{*}-\mathrm{N}_{2}{ }^{*}-\mathrm{TMA}$ & 3.0 & 8.0 & 34.5 & 40.0 & 14.5 \\
\hline
\end{tabular}

As DEPA* should be able to incorporate nitrogen by itself, the intermediate plasma is not needed for the deposition of a nitrogen doped $\mathrm{Al}$ phosphate. Indeed, 3 at. $\%$ of nitrogen is present in the film grown from the DEPA*-TMA process, but unfortunately there is also a lot of carbon contamination (18 at.\%). Oxygen plasma can be used to remove the carbon contamination, but similar to what was seen with TMP*, it also removes nitrogen. The composition and GPC $(0.6 \mathrm{~nm} /$ cycle $)$ of a thin film deposited from the DEPA*-O ${ }_{2}{ }_{-}$TMA 
process is however very close to the undoped phosphate reported by Dobbelaere et al. ${ }^{24}$. This demonstrates that rapid ALD growth of an $\mathrm{Al}$ phosphate is not restricted to the use of TMP plasma as the phosphorus precursor. When only a nitrogen plasma is used, the nitrogen content increases to 8 at.\%, which is similar to what is seen with TMP*.

Table 2: Atomic concentrations of (N-doped) Al phosphate measured with ERD. Nitrogen concentration was not tabulated in the work of Dobbelaere et al. ${ }^{[24}$. The uncertainty on the atomic concentration is discussed in the experimental section.

\begin{tabular}{|c|c|c|c|c|c|}
\hline Deposition process & C (at.\%) & $\mathrm{N}($ at. $\%)$ & $P($ at.\%) & $\mathrm{O}($ at. $\%)$ & Al (at.\%) \\
\hline $\mathrm{TMP}^{*}{ }_{-} \mathrm{O}_{2}{ }^{*}-\mathrm{TMA}(\mathrm{ERD})^{24}$ & 2.2 & / & 20.2 & 67.8 & 11.3 \\
\hline $\mathrm{TMP}^{*} \mathrm{~N}_{2}{ }^{*}-\mathrm{TMA}(\mathrm{ERD})$ & 0.6 & 7.7 & 25.9 & 51.7 & 9.4 \\
\hline DEPA*-N ${ }_{2}{ }_{-}$TMA (ERD) & 2.1 & 7.9 & 28.4 & 46.6 & 7.9 \\
\hline
\end{tabular}

However, as there could be a large error on the atomic concentration measured by XPS, a more reliable technique (elastic recoil detection ${ }^{29}$, or ERD) was used for the two most nitrogen rich materials. The film thickness for each sample was around $60 \mathrm{~nm}$. The ERD depth
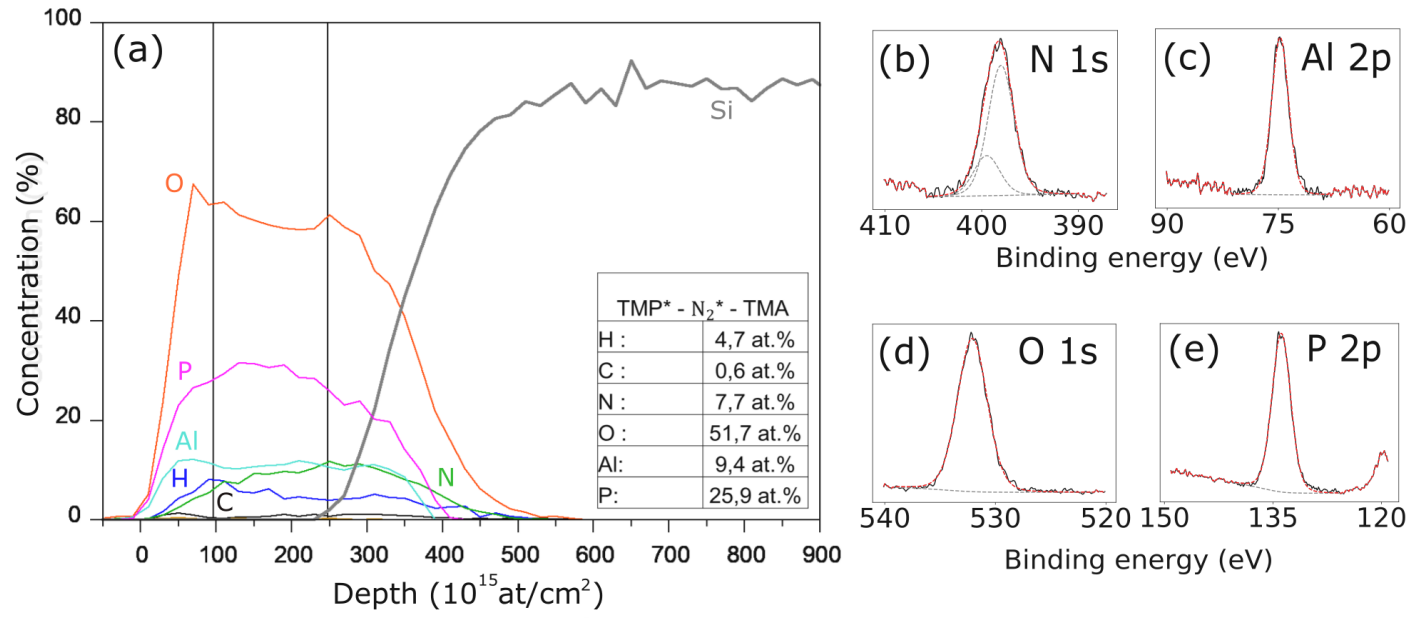

Figure 6: (a) ERD profile of N-doped Al phosphate from the deposition using $\mathrm{TMP}^{*} \mathrm{~N}_{2}{ }_{-}$ TMA with atomic concentrations and XPS spectra of the (b) N 1s, (c) Al 2p, (d) O 1s and (e) $\mathrm{P} 2 \mathrm{p}$ peaks. The $\mathrm{N}$ 1s peak was fitted with two peaks resembling doubly and triply coordinated nitrogen. 

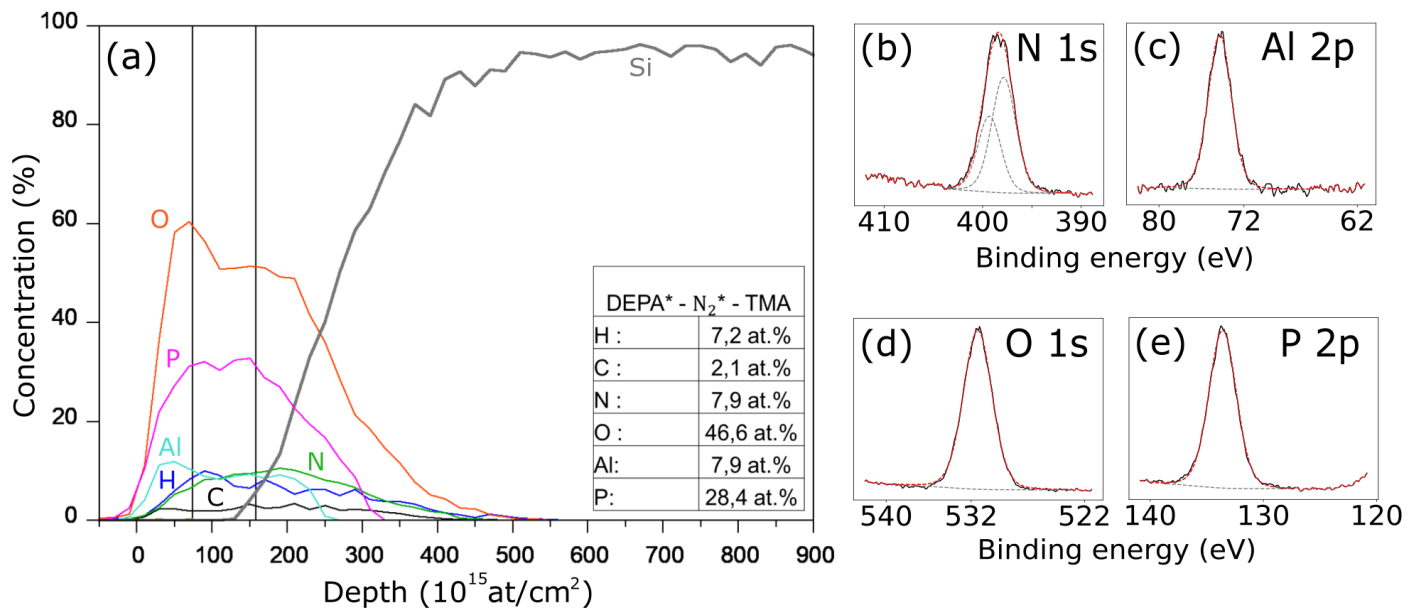

Figure 7: (a) ERD profile of $\mathrm{N}$-doped Al phosphate from the deposition using $\mathrm{DEPA}^{*} \mathrm{~N}_{2}{ }^{*}$ TMA with atomic concentrations and XPS spectra of the (b) N 1s, (c) Al 2p, (d) O 1s and (e) $\mathrm{P} 2 \mathrm{p}$ peaks. The $\mathrm{N}$ 1s peak was fitted with two peaks resembling doubly and triply coordinated nitrogen.

profiles in figures 6 and 7 and atomic concentrations in table 2 show that the composition of the film using TMP is uniform throughout the whole layer, with an average nitrogen level of 7.7 at.\%. A similar nitrogen content of 7.9 at.\% is measured using DEPA*. From the $\mathrm{P} / \mathrm{Al}$ ratio of the undoped phosphate (1.8), it can be seen that its stoichiometry is closer to an aluminium pyrophosphate $\left(\mathrm{Al}_{4} \mathrm{P}_{6} \mathrm{O}_{21}\right.$, with a $\mathrm{P} / \mathrm{Al}$ of 1.5$)$ than to $\mathrm{AlPO}_{4}$ (with a $\mathrm{P} / \mathrm{Al}$ ratio of 1 ). This ratio further increases to 2.8 for the TMP* $-\mathrm{N}_{2}{ }^{*}-$ TMA process and 3.6 for the DEPA* $-\mathrm{N}_{2}{ }^{*}-$ TMA. This increase upon nitrogen doping was expected based on earlier studies in lithium phosphate ${ }^{21}$, where the $\mathrm{P} / \mathrm{Li}$ ratio showed a gradual increase with the incorporation of nitrogen.

Chemical bond structure. Comparing the TMP*- ${ }^{*}{ }_{2}$-TMA process with the undoped reference, it can be seen that more oxygen is removed than nitrogen is added. This could mean that during the reaction with the nitrogen plasma, multiple oxygen atoms per nitrogen atom have been removed. In the work of Kozen et al. ${ }^{21}$, who combined a nitrogen plasma with TMP vapour for the deposition of LiPON, nitrogen plasma showed to cross-link 
phosphorus atoms of the chemisorbed TMP molecules through the removal of one of their methoxy $\left(-\mathrm{OCH}_{3}\right)$ groups. This means that, aside from the normal P-O-P crosslinking in phosphate glasses, the incorporation of nitrogen leads to a P-N-P type of crosslinking. In the last process step, the lithium containing precursor would then react with the remaining ligands of the TMP molecule for the formation of a lithium phosphorus oxynitride glass. In such a structure, nitrogen was then either bound to two phosphorus atoms $(-\mathrm{N}=)$, or three phosphorus atoms $(-\mathrm{N}<)$. The surface layer resulting from a TMP plasma (rather than a vapour) consists of a complex mix of phosphate esters, in which the chemisorbed molecule could be terminated by a methoxy and/or a hydroxyl (-OH) group ${ }^{24}$. This means that such a cross-linking reaction could be taking place here as well, by sacrificing two (or more) methoxy groups for the incorporation of one nitrogen. As a TMP plasma also contains molecular components that are -OH terminated, the remaining hydroxyl groups could then be used in the last process step to incorporate aluminium through the basic reaction of TMA.

This assumption is also confirmed when analysing the $\mathrm{N}$ 1s peak shape in XPS (figure 6b). The peak can be fitted with two components at $398.2 \mathrm{eV}$ and $399.7 \mathrm{eV}$, which are close to what is expected for respectively doubly $(-\mathrm{N}=)$ and triply $(-\mathrm{N}<)$ coordinated nitrogen in a phosphorus oxynitride glass (similar to previous work on $\operatorname{LiPON}^{21,28, \frac{32}{32}, 33}$ ). As the other elements ( $\mathrm{Al} 2 \mathrm{p}$ at $74.4 \mathrm{eV}, \mathrm{O} 1 \mathrm{~s}$ at $532.0 \mathrm{eV}$ and $\mathrm{P} 2 \mathrm{p}$ at $133.7 \mathrm{eV}$ ) do not differ greatly from what is expected from an undoped $\mathrm{Al}$ phosphate $\mathrm{en}^{34}$, we expect that a phosphorus oxynitride structure (similar to LiPON) might have been formed during the nitrogen plasma exposure. When looking at the $\mathrm{N}$ 1s peak of the film deposited using DEPA* (figure $7 \mathrm{~b}$ ), it can be seen that the triply coordinated nitrogen component has increased with respect to the film deposited using TMP*. As DEPA* is capable of incorporating nitrogen as well, we expect that his is the main source for the additional triply coordinated nitrogen bonds. As discussed earlier, this difference in the amount of triply coordinated nitrogen could explain differences in the growth rate between the different (N-doped) phosphates. It has to be noted however 
that only the surface of the film has been analysed, as charging of the sample did not allow for a detailed study of bulk material ${ }^{35}$.

From the composition, it can also be seen that the $\mathrm{P} / \mathrm{N}$ ratio is far from one for both films grown with $\mathrm{TMP}^{*}$ and $\mathrm{DEPA}^{*}$, which is in contrast with the expectations from the work of Kozen et $\mathrm{al}^{21}$. As explained earlier, the nitrogen plasma mainly attacks the methoxy groups from the TMP molecules that are on the surface, linking two separate molecules. However, as described by Dobbelaere et al, the layer resulting from a TMP plasma (rather than TMP vapour) is a much more complex mixture of phosphate esters. Some bonds in these esters, such as P-O-P bonds, are possibly too strong to be completely replaced by nitrogen related bonds, increasing the $\mathrm{P} / \mathrm{N}$ ratio. In the case of $\mathrm{DEPA}^{*}, \mathrm{P} / \mathrm{N}$ ratio $>1$ could mean that some $\mathrm{P}-\mathrm{NH}_{2}$ bonds are broken during the plasma phase, possibly forming stronger bonds such as a bridging oxygen bond. Next to this, an increase of the P/Al ratio (as mentioned earlier) and the $\mathrm{P} / \mathrm{O}$ ratio is found for both layers. This is consistent with a model in which the methoxy groups of the chemisorbed phosphate esters are sacrificed for the cross-linking of the phosphorus atoms using nitrogen bonds (as there is a removal of oxygen, and these ligands are then no longer available for reactions with TMA).

No differences bigger than $0.3 \mathrm{eV}$ in binding energy were found between N-doped $\mathrm{Al}$ phosphate deposited with TMP and DEPA (figure 6 and 7), showing that the final structure is relatively similar. However, no complete conclusion could be drawn from the peak positions due to the damaging/charging effect at deeper levels of the film (due to the sputtering using $\mathrm{Ar}^{+}$ions), hence only allowing for the top layer to be studied.

Film crystallinity. Using XRD, it can be seen that N-doped Al phosphate deposited with TMP* is amorphous as deposited (figure 8). However, upon annealing up to $950^{\circ} \mathrm{C}$ in a He atmosphere, diffraction peaks appear. These new peaks could be linked to crystalline 
$\mathrm{AlPO}_{4}$, showing that even after nitrogen doping, the phosphate structure is still maintained to a certain degree. $\mathrm{N}$-doped $\mathrm{Al}$ phosphate deposited with DEPA* is also amorphous. Upon annealing, the same peaks arise showing the similarities between the films deposited with $\mathrm{TMP}^{*}$ and DEPA*.

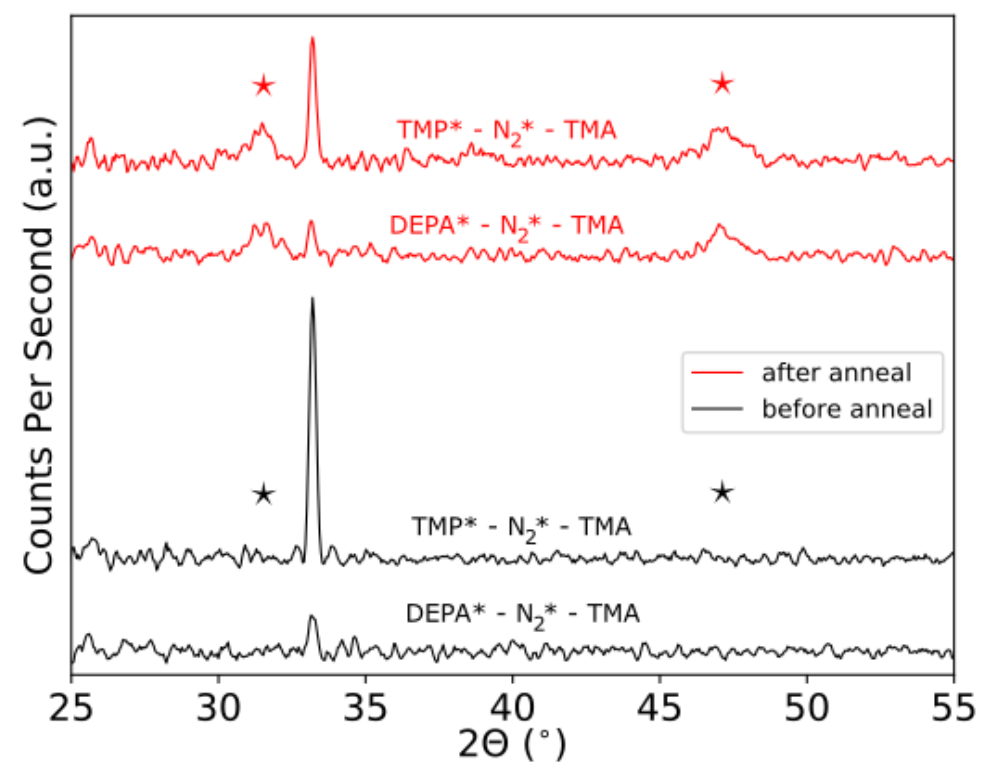

Figure 8: XRD spectrum of N-doped Al phosphate using TMP and DEPA as phosphorus precursor before and after anneal in He atmosphere. Stars denote position where $\mathrm{AlPO}_{4}$ peaks are expected based on the work of Han et al ${ }^{[36}$. Unlabelled peaks are substrate related. Film thickness for both films is approximately $65 \mathrm{~nm}$.

\section{Electrochemical characterisation}

Next, the electrical and electrochemical properties of the N-doped aluminium phosphate with the highest growth rate, i.e. the films resulting from the DEPA*-N ${ }_{2}{ }_{-}$TMA process, were examined and benchmarked against undoped aluminum phosphate from the TMP*-O${ }_{2}{ }_{-}$TMA process. The ionic conductivity for lithium ions was probed by applying these coatings on top of a lithium-ion electrode reference film, in this case a $40 \mathrm{~nm} \mathrm{TiO}_{2}$ film, while ferrocene was used to study the electronic conductivity of the coating on a conductive TiN film. 
Ionic conductivity on $\mathrm{TiO}_{2}$. For an aluminum phosphate applied to the $\mathrm{TiO}_{2}$ substrate, it was found that coatings thicker than approximately $2 \mathrm{~nm}$ are not transmissive to $\mathrm{Li}^{+}$-ion (no peaks appear in the cyclic voltammogram in figure S3a). It is only when the electrode is cycled down to $0.5 \mathrm{~V}_{\text {vs }} \mathrm{Li}^{+} / \mathrm{Li}$ that a large peak appears, as shown in in figure S3a. After this, the coating appears to have been 'activated', showing that $\mathrm{Li}^{+}$-ions can diffuse through the coating. This 'activation' behaviour was also observed by Dobbelaere et al. in ealier work on PE-ALD phosphates which were evaluated as battery electrode materials ${ }^{17,25}$. For $\mathrm{Al}$ phosphate in particular, Shi et al. ${ }^{14}$ found that the coating on $\mathrm{LiMn}_{1.5} \mathrm{Ni}_{0.5} \mathrm{O}_{4}$ (LMNO) particles showed increasing transmittance during cycling, which could result from a similar activation process to what is shown here. If, in this work, the (N-doped) Al phosphate coating was thin enough, the activation was not needed, and the $\mathrm{TiO}_{2}$ peaks already appeared in the first cycle (figure S4a). With this activation in mind, two different coating thicknesses were studied for the (un)doped $\mathrm{Al}$ phosphate.

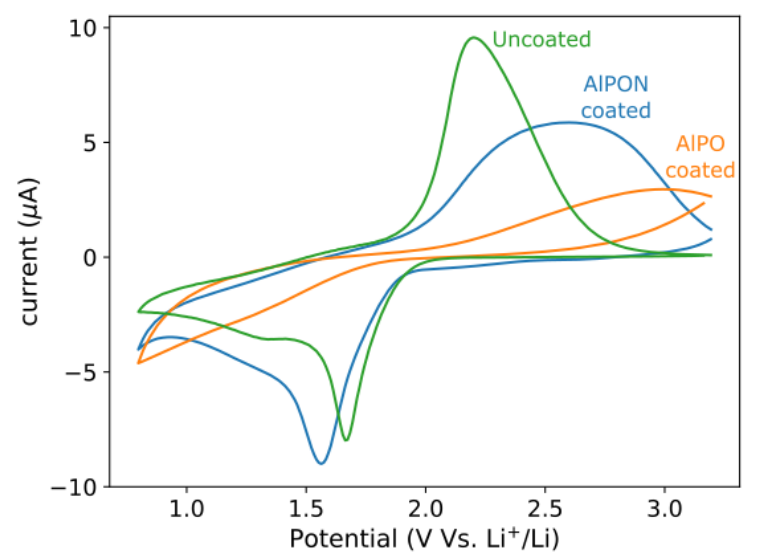

Figure 9: Cyclic voltammograms of $\mathrm{TiO}_{2}$ coated with either 3 cycles of $\mathrm{N}$-doped $\mathrm{Al}$ phosphate (denoted as AlPON) or 7 ALD cycles of undoped Al phosphate (denoted as AlPO). The amount of ALD cycles were chosen so that a similar coating thickness for both materials, targeted to be approximately $4 \mathrm{~nm}$, could be obtained. The different voltammograms show the blocking effect of the coatings for $\mathrm{Li}^{+}$-ions with respect to the uncoated electrode but improvement upon nitrogen doping. The cell is cycled at a scan rate of $1 \mathrm{mV} / \mathrm{s}$ between 0.8 $\mathrm{V}$ and $3.5 \mathrm{~V}$ vs $\mathrm{Li}^{+} / \mathrm{Li}$ 
The cyclic voltammogram of $\mathrm{TiO}_{2}$ with and without a coating with a targeted thickness of $4 \mathrm{~nm}$ (by performing either $3 \mathrm{ALD}$ cycles of $\mathrm{N}$-doped Al phosphate or 7 cycles of undoped Al phosphate) is shown in figure 9 (after activation at low potential). The peak shift in both coated systems with respect to the uncoated electrode shows that the coatings have an ionically blocking effect. However, nitrogen doping of the phosphate appears to increase diffusion of lithium ions through the coating, as the peak shift is smaller after doping.

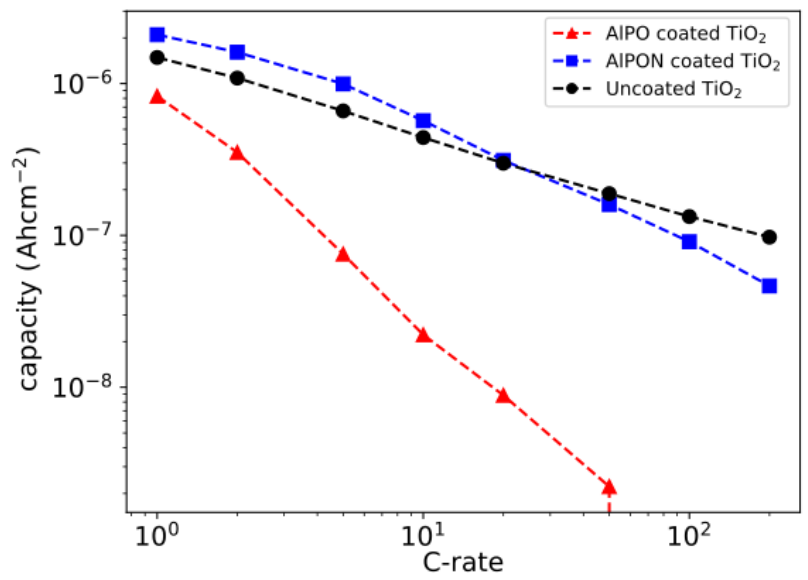

Figure 10: Lithiation capacity of (un)coated $\mathrm{TiO}_{2}$ with a targeted coating thickness of approximately $4 \mathrm{~nm}$ ( 3 cycles of AlPON and 7 cycles of AlPO) for both phosphates. The capacity was measured after activation at low potential.

The capacity at different C-rates was also measured, in which both coatings show to hamper the kinetics of the electrode (figure 10). However, a significant improvement in kinetics is seen when going from a regular $\mathrm{Al}$ phosphate to $\mathrm{N}$-doped $\mathrm{Al}$ phosphate. This implies that the nitrogen doping decreases the ionic resistance of the coating. This increase in ionic conductivity upon nitrogen doping is also seen in a Li-phosphate system. For LiPON, the proposed mechanism for an increased ionic conductivity is a decrease in the bridging/nonbridging oxygen ratio ${ }^{37}$. This could also be the cause in this case if the nitrogen plasma is able to attack P-O-P bonds during the deposition. 
However, as the activation of a thicker coating at a low potential could potentially harm the electrode, this should be avoided. A possible way of doing this, is by decreasing the coating thickness. As mentioned earlier, no activation was needed for approximately $1 \mathrm{~nm}$ thick coatings, which is why only these thicknesses were studied further.

For coatings with a lower thickness (i.e. in the order of $1 \mathrm{~nm}$ from 1 ALD cycle for N-doped $\mathrm{Al}$ phosphate, or $2 \mathrm{ALD}$ cycles for undoped $\mathrm{Al}$ phosphate), the electrode is still partially blocked, but no activation was needed. As can be seen in figure S4, the improvement in capacity upon nitrogen doping is however not visible any more. Although being indistinguishable in this measurement, a small difference in capacity of both coated electrodes could become more pronounced when it is transferred to a system that requires higher current, such as a powder based electrode. As the voltage drop over the coating (current $*$ coating resistance) will increase with increasing current, the difference in electrochemical performance of coatings with only a small difference in ionic resistance (which is expected here for the 1 nm coatings) will become more pronounced. For this reason, it is important to get a more detailed view on the coating resistance at this thickness scale, which was done by performing a cyclic voltammetry (CV) peak analysis.

If the working electrode is a reversible system, as is $\mathrm{TiO}_{2}$, the voltage drop (i.e. IR-drop) that is present over the coating can be studied by measuring the peak potential and peak current at a set of different scan rates. Due to this IR-drop that is imposed to the system (either internal resistance or coating resistance), the peak potential will shift with increasing scan rate, and a linear relation between the peak current and peak potential will be found. At low enough scan rates, this linear behaviour of the peak current versus the peak potential is found for the (un)coated systems (figure 11). At higher scan rates (higher than 20 $\mathrm{mV} / \mathrm{s}$ ), there is no longer linearity implying that the shift at those scan rates is not IR-drop dominated and this region was omitted. 

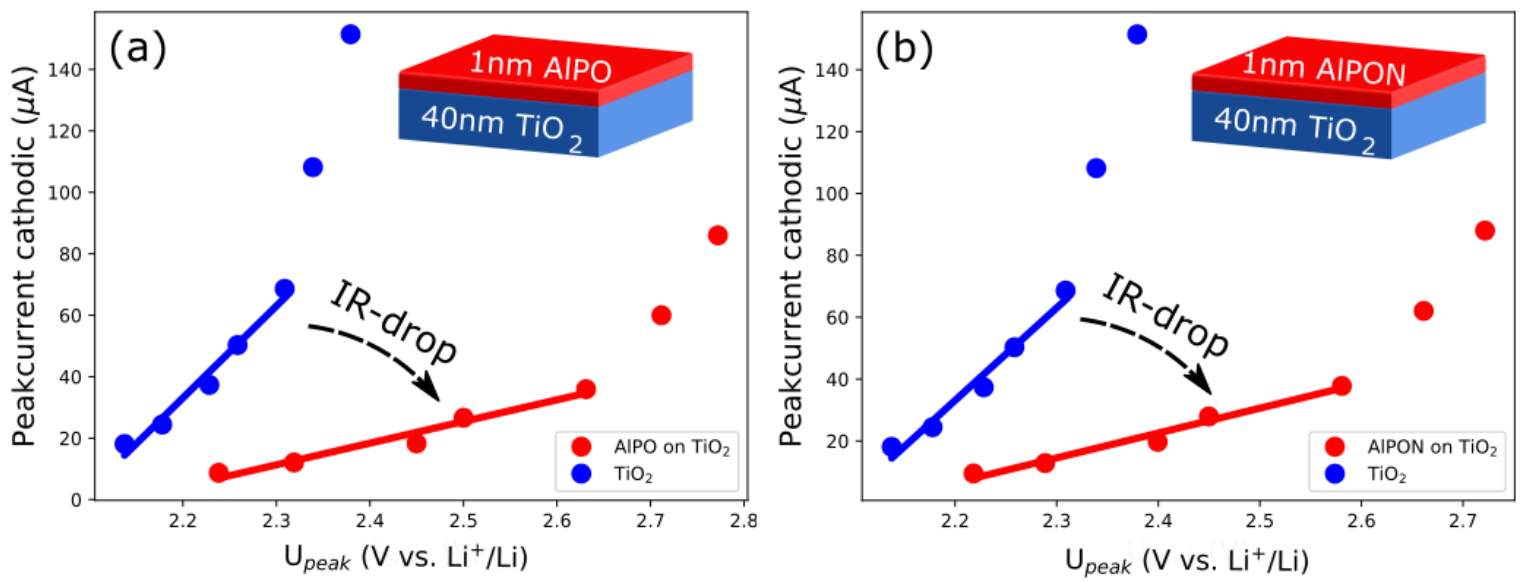

Figure 11: Calculation of the resistance for both (a) 2 ALD cycles of Al phosphate and (b) 1 ALD cycle of $\mathrm{N}$-doped $\mathrm{Al}$ phosphate. A similar coating thickness of approximately $1 \mathrm{~nm}$ was targeted for both materials. The measured resistances are $(14.2 \pm 2.8) \mathrm{k} \Omega$ for the electrode coated with undoped $\mathrm{Al}$ phosphate (denoted as AlPO) and $(12.4 \pm 2.0) \mathrm{k} \Omega$ for the electrode coated with $\mathrm{N}$-doped $\mathrm{Al}$ phosphate (denoted as AlPON). The resistance of the uncoated $\mathrm{TiO}_{2}$ electrode is $(3.3 \pm 0.6) \mathrm{k} \Omega$.

When a linear fit is performed in the potential range up to $20 \mathrm{mV} / \mathrm{s}$, a measure for the resistance of the system can be obtained by means of the inverse slope of this line. The difference between the resistance of the uncoated system and the coated system is then assumed to be the coating resistance. As this resistance is also dependent on the electrode surface area and coating thickness, an effective transversal conductivity was calculated. This is not seen as the actual ionic conductivity (as this is not a bulk material), but does provide a better view on the coating kinetics. From these calculations, an effective conductivity of $(1.3 \pm 0.4) * 10^{-8} \mathrm{mS} / \mathrm{cm}$ for undoped phosphate and $(1.6 \pm 0.4) * 10^{-8} \mathrm{mS} / \mathrm{cm}$ for N-doped Al phosphate was found. This shows that the conductivity seems to have slightly increased upon nitrogen doping, but no conclusive answer is possible due to the large error margins. As explained earlier, it is expected that the effect of doping will become more clear in systems that require a higher current (similar to what was seen at higher coating thickness in figure 9). 
Electronic conductivity on TiN. If a reversible redox system can be found in which electrons are exchanged, instead of Li-ions, the electronic conductivity of the coating could be measured in a similar way as the ionic conductivity. The system chosen here is a TiN film as the working electrode, Pt-wire as the counter and reference electrode and a ferrocene electrolyte. The redox active species (ferrocene) will then donate electrons to and accept electrons from the electrode. Starting from this electrochemical activity, a measure of the internal electronic resistance can again be obtained by cycling the system at different scan rates.

When the TiN is coated with (N-doped) Al phosphate, the change in resistance can be translated into an effective electronic conductivity of the coating (figure S7). This showed that by doping the phosphate with nitrogen, the effective electronic conductivity increased from $(4.7 \pm 1) * 10^{-8} \mathrm{mS} / \mathrm{cm}$ to $(1.7 \pm 0.2) * 10^{-7} \mathrm{mS} / \mathrm{cm}$. This increase upon N-doping is similar to what is seen in the LiPON structure ${ }^{22}$, where the increase was ascribed to a decrease in bridging oxygen and an increase in the cross-linking density of the phosphate glass. The results in this work are thought to be very similar, although this was not further investigated.

\section{PE-ALD nitrogen-doped aluminium phosphate films as functional coatings.}

To further prove the possibilities of the newly developed nitrogen doping process, the (un)doped coating was applied on a lithium nickel manganese cobalt oxide (NMC) powder. In a first test, to see if the material of interest can be deposited, approximately $20 \mathrm{~nm}$ of $\mathrm{N}$-doped $\mathrm{Al}$ phosphate was deposited. This was then studied by SEM and EDX, as shown in figure12. In the SEM images, there is no clear sign of a coating on the particle surface. However, looking at the EDX spectrum at the particle surface, a clear phosphorus and aluminium peak can be found, showing successful deposition on the particle surface. 

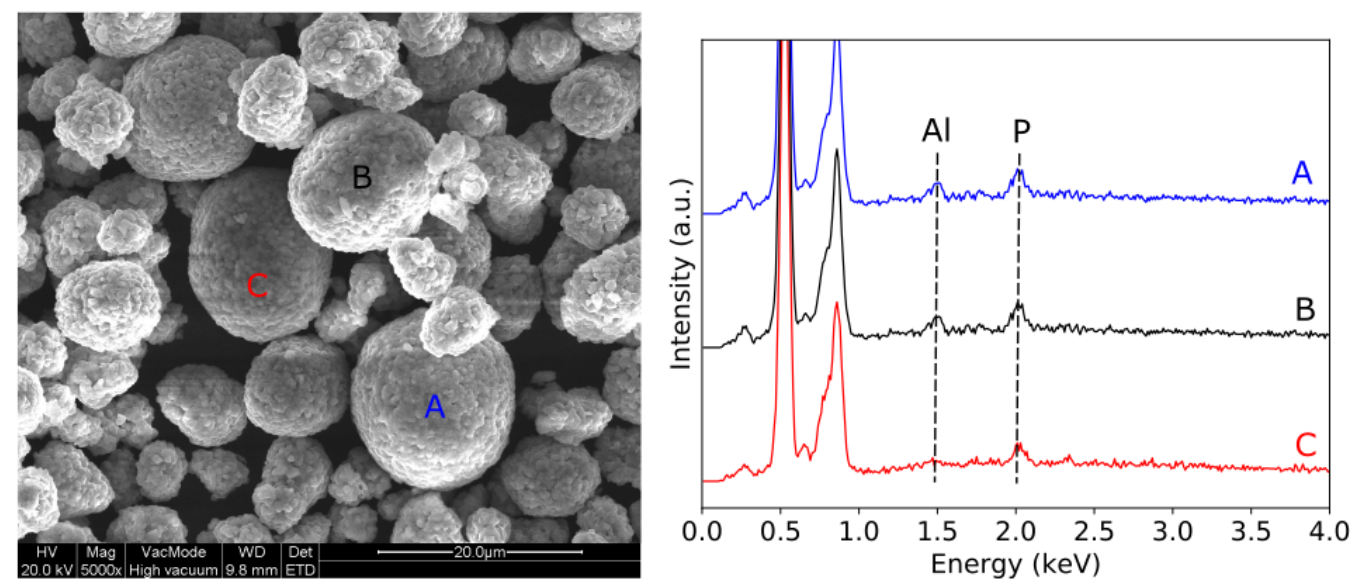

Figure 12: N-doped aluminium phosphate on NMC powder, studied with (left) SEM and (right) EDX. The EDX spectrum was measured for 100s with a $10 \mathrm{kV}$ acceleration voltage.

The powder was then coated with approximately $1 \mathrm{~nm}$ of (N-doped) Al phosphate (already achieved after respectively 1 and 2 ALD cycles), and used as an electrode in a coin cell. The voltage profiles and discharge energy of coated and uncoated cells at different C-rates $(\mathrm{C} / 5, \mathrm{C} / 2,1 \mathrm{C}, 2 \mathrm{C}$ and $5 \mathrm{C})$ is shown in figure 13 . The coating without nitrogen doping clearly has a negative impact on the electrode, as there is a large decrease in the energy density at high $\mathrm{C}$-rates (figure 13a). The $\mathrm{N}$-doped $\mathrm{Al}$ phosphate coating however improves the battery performance at higher C-rates. In the voltage profiles in figure $13 \mathrm{~b}$, it can be seen that all plateaus and inflection points found in the pristine material are also present in the material coated with $\mathrm{N}$-doped $\mathrm{Al}$ phosphate. No additional ones were found, indicating that the coating itself is only transmitting the lithium ions, and not storing them. The electrochemical storage nature of the electrode material itself has thus not been altered by the process of the coating. This means that the improved rate capability mainly originates from a reduced voltage drop at increasing currents, enhancing the energy density. Such an effect could be expected from the elimination of side-reactions that are detrimental to the electrode performance. The effect is even more clear at higher loadings of active material (figure S8). From this, it can be clearly seen that the $\mathrm{Al}$ phosphate coating itself has improved upon 


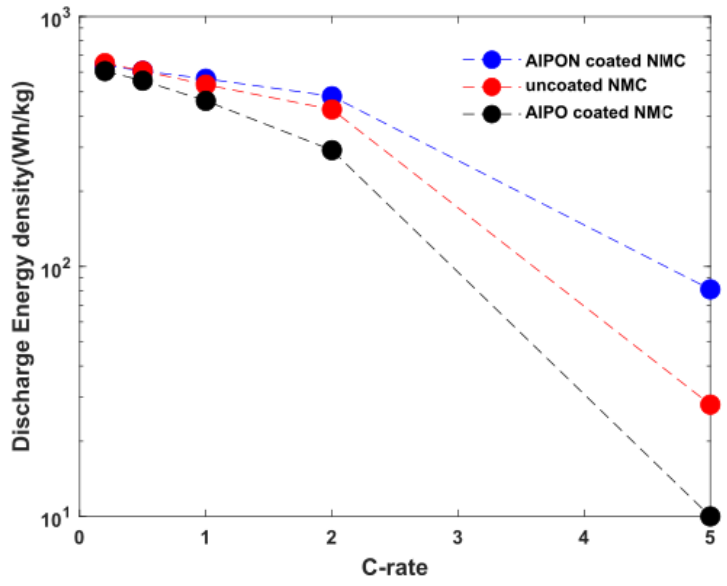

(a)

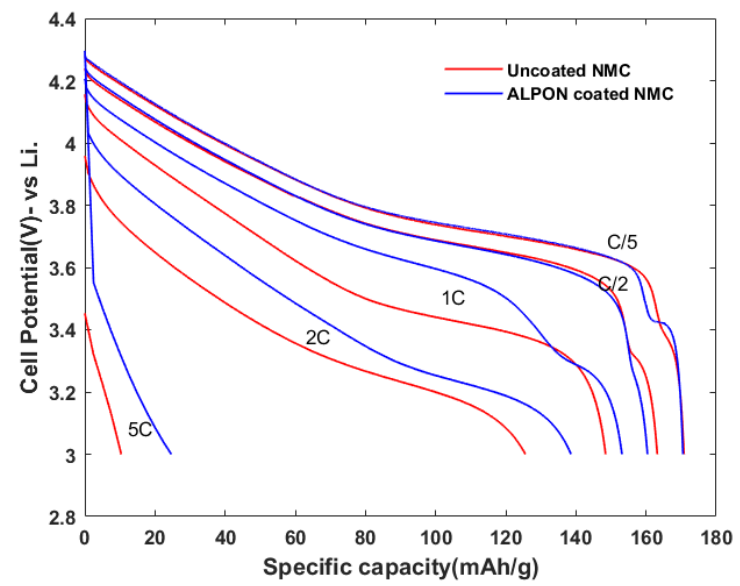

(b)

Figure 13: (a) Energy density of (un)coated NMC powder electrodes at different C-rates and (b) voltage profiles of (un)coated NMC at different C-rates. The loading of active material is $13.8 \mathrm{mg} / \mathrm{cm}^{2}$.

nitrogen doping. Even more important is however that the interface modification (only one deposition cycle of the newly developed PE-ALD process) reduces the voltage drop at high current, allowing for improved rate capability of the NMC electrode.

The stability of the electrode was then investigated by cycling the (un)coated cells for 100 cycles at a C-rate of 1C. During cycling, the capacity (figure 14a of the Al phosphate coated electrode is significantly below the two other electrodes due to its blocking nature. Although the capacity of the electrode coated with $\mathrm{N}$-doped $\mathrm{Al}$ phosphate is very similar to the pristine sample, the voltage profiles in figure $14 \mathrm{~b}$ show that this coating does improve the stability of the electrode (the voltage profiles of NMC coated with undoped Al phosphate is shown in figure S9a). While the uncoated electrode clearly suffers from an increasing voltage drop upon cycling, the voltage profiles of the coated electrodes remain more stable. As can be seen in figure S9b, this translates into an improved stability of the energy density. A possible explanation for this could again be the suppression of unwanted side-reactions that are detrimental to the stability of the electrode. As phosphates typically provide a good thermal stability, this capacity/energy density retention might even further improve at higher operat- 


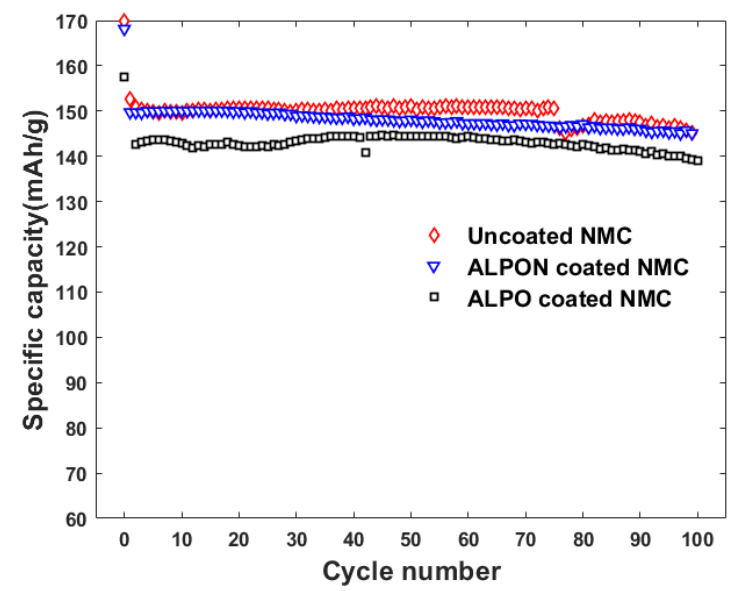

(a)

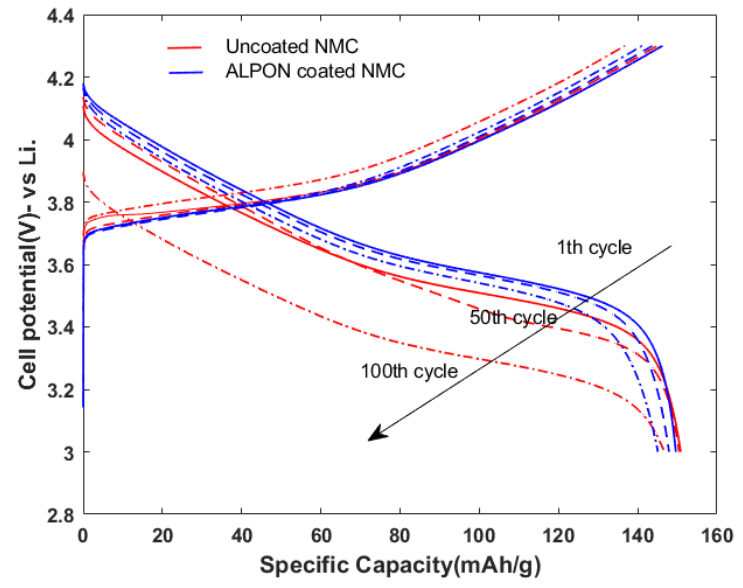

(b)

Figure 14: Evolution of (a) the capacity of (un)coated NMC during 100 cycles at $1 \mathrm{C}$ and (b) the voltage profiles of the 1st, 50th and 100th cycle of NMC coated with and without nitrogen doped $\mathrm{Al}$ phosphate. The loading of active material is $13.8 \mathrm{mg} / \mathrm{cm}^{2}$.

ing temperatures, but this was not studied here. From this we can see that nitrogen doping has electrochemically improved the phosphate, and that a single ALD cycle of the newly developed process was enough to improve both the energy efficiency and rate capability of the NMC electrode.

\section{Conclusion}

In this work, nitrogen doping of $\mathrm{Al}$ phosphate was achieved in two different ways. The first process is based on the deposition process of undoped metal phosphate, in which the oxygen plasma is now replaced by a nitrogen plasma. This allows for the rapid growth with a nitrogen doping level of 7.7 at.\%. The addition of an extra oxygen plasma again removes the nitrogen dopants. A second process is based on the presence of an amine group in the phosphate precursor DEPA, of which the plasma polymerisation showed similar reaction properties to TMP. When TMP* is replaced by DEPA*, a similar nitrogen content (7.9 at.\%) was found, but the GPC almost doubled. The intermediate nitrogen plasma could also be eliminated in this case (as DEPA* is able to incorporate nitrogen by itself), but as the films resulting 
from the simplified process also showed to have a high carbon contamination, only the more complete process (i.e. DEPA* $-\mathrm{N}_{2} *-$ TMA) was further investigated.

When coating a $\mathrm{TiO}_{2}$ electrode with (un)doped $\mathrm{Al}$ phosphate, it is seen that for high coating thickness (i.e. thickness higher than $2 \mathrm{~nm}$ ), an electrochemical activation is needed. In these systems, a significant improvement in ionic resistance was seen after nitrogen doping. For lower coating thickness, the activation is not needed and an effective ionic conductivity of $(1.3 \pm 0.4) * 10^{-8} \mathrm{mS} / \mathrm{cm}$ for undoped $\mathrm{Al}$ phosphate and $(1.6 \pm 0.4) * 10^{-8} \mathrm{mS} / \mathrm{cm}$ for N-

doped Al phosphate is found. Next to this, the effective electronic conductivity significantly increased from $(4.7 \pm 1) * 10^{-8} \mathrm{mS} / \mathrm{cm}$ to $(1.7 \pm 0.2) * 10^{-7} \mathrm{mS} / \mathrm{cm}$. Only one cycle of the novel nitrogen doped aluminium phosphate coating showed to increase the energy density of NMC powder at high C-rates. Although the evolution in capacity upon cycling did not change dramatically after coating, a more stable energy density is observed by means of a reduced voltage drop during cycling. These results help for a better understanding on the different ways to improve existing functional coatings.

\section{Supporting information}

Supporting information is available, containing (1) Visualisation of the DEPA plasma components, (2) additional XPS analysis, (3) cyclic voltammogram and rate capability of (un)coated $\mathrm{TiO}_{2}$ electrodes with a low coating thickness, (4) study on the validity of the CV-scan method, (5) results of CV-scan method for electronic conductivity, (6) additional electrochemical results for powder-based electrodes.

\section{Keywords}

Atomic layer deposition, Plasma-enhanced deposition, Nitrogen doping, Aluminium phosphate, Lithium-ion battery. 


\section{Acknowledgements}

The authors are grateful for financial support to FWO-Vlaanderen and the Special Research Fund BOF of Ghent University (GOA project, Grant No. 01G01513, and SBO XL-Lion, S005017N). M. M. and J.D. acknowledge FWO-Vlaanderen for a post-doctoral fellowship.

\section{References}

(1) Liu, C.; Neale, Z.; Cao, G. Understanding Electrochemical Potentials of Cathode Materials in Rechargeable Batteries. Materials Today 2016, 19, 109-123.

(2) Li, W.; Song, B.; Manthiram, A. High-Voltage Positive Electrode Materials for LithiumIon Batteries. Chemical Society Reviews 2017, 46, 3006-3059.

(3) Yu, X.; Chen, X.; Buchholz, D.; Li, Q.; Wu, J.; Fenter, P.; Bedzyk, M.; Dravid, V.; Barnett, S. Pulsed Laser Deposition and Characterization of Heteroepitaxial $\mathrm{LiMn}_{2} \mathrm{O}_{4} / \mathrm{La}_{0.5} \mathrm{Sr}_{0.5} \mathrm{CoO}_{3}$ Bilayer Thin Films as Model Lithium Ion Battery Cathodes. ACS Applied Nano Materials 2018, 1, 642-653.

(4) Zhang, Y. Spinel $\mathrm{LiMn}_{2} \mathrm{O}_{4}$ with Two-step Nano- $\mathrm{Al}_{2} \mathrm{O}_{3}$ Coating as High Performance Positive Materials. International Journal of Electrochemical Science 2017, 6853-6862.

(5) Wise, A.; Ban, C.; Weker, J.; Misra, S.; Cavanagh, A.; Wu, Z.; Li, Z.; Whittingham, M.; $\mathrm{Xu}$, K.; George, S.; Toney, M. Effect of $\mathrm{Al}_{2} \mathrm{O}_{3}$ Coating on Stabilizing $\mathrm{LiNi}_{0.4} \mathrm{Mn}_{0.4} \mathrm{Co}_{0.2} \mathrm{O}_{2}$ Cathodes. Chemistry of Materials 2015, 27, 6146-6154.

(6) Mattelaer, F.; Vereecken, P.; Dendooven, J.; Detavernier, C. The Influence of Ultrathin Amorphous ALD Alumina and Titania on the Rate Capability of Anatase $\mathrm{TiO}_{2}$ and $\mathrm{LiMn}_{2} \mathrm{O}_{4}$ Lithium Ion Battery Electrodes. Advanced Materials Interfaces 2017, 4, 1601237. 
(7) Li, X.; Liu, J.; Meng, X.; Tang, Y.; Banis, M.; Yang, J.; Hu, Y.; Li, R.; Cai, M.; Sun, X. Significant Impact on Cathode Performance of Lithium-ion Batteries by Precisely Controlled Metal Oxide Nanocoatings via Atomic Layer Deposition. Journal of Power Sources 2014, 247, 57-69.

(8) Wang, H.; Wang, F. Electrochemical Investigation of an Artificial Solid Electrolyte Interface for Improving the Cycle-Ability of Lithium Ion Batteries Using an Atomic Layer Deposition on a Graphite Electrode. Journal of Power Sources 2013, 233, 1-5.

(9) Liu, H.; Cheng, C.; Zongqiuhu; Zhang, K. The Effect of ZnO Coating on $\mathrm{LiMn}_{2} \mathrm{O}_{4} \mathrm{Cycle}$ Life in High Temperature for Lithium Secondary Batteries. Materials Chemistry and Physics 2007, 101, 276-279.

(10) Zhang, C.; Liu, X.; Su, Q.; Wu, J.; Huang, T.; Yu, A. Enhancing Electrochemical Performance of $\mathrm{LiMn}_{2} \mathrm{O}_{4}$ Cathode Material at Elevated Temperature by Uniform Nanosized $\mathrm{TiO}_{2}$ Coating. ACS Sustainable Chemistry \& Engineering 2016, 5, 640-647.

(11) Zeng, J.; Li, M.; Li, X.; Chen, C.; Xiong, D.; Dong, L.; Li, D.; Lushington, A.; Sun, X. A novel Coating onto $\mathrm{LiMn}_{2} \mathrm{O}_{4}$ Cathode with Increased Lithium Ion Battery Performance. Applied Surface Science 2014, 317, 884-891.

(12) Cho, J.; Kim, T.; Kim, J.; Noh, M.; Park, B. Synthesis, Thermal, and Electrochemical Properties of $\mathrm{AlPO}_{4}$-Coated $\mathrm{LiNi}_{0.8} \mathrm{Co}_{0.1} \mathrm{Mn}_{0.1} \mathrm{O}_{2}$ Cathode Materials for a Li-ion Cell. Journal of The Electrochemical Society 2004, 151, A1899.

(13) Cho, J.; Kim, Y.; Kim, B.; Lee, J.; Park, B. A Breakthrough in the Safety of Lithium Secondary Batteries by Coating the Cathode Material with $\mathrm{AlPO}_{4}$ Nanoparticles. Angewandte Chemie International Edition 2003, 42, 1618-1621.

(14) Shi, J.; Yi, C.; Kim, K. Improved Electrochemical Performance of $\mathrm{AlPO}_{4}$-Coated $\mathrm{LiMn}_{1.5} \mathrm{Ni}_{0.5} \mathrm{O}_{4}$ Electrode for Lithium-ion Batteries. Journal of Power Sources 2010, 195, 6860-6866. 
(15) Liu, D.; He, Z.; Liu, X. Increased Cycling Stability of $\mathrm{AlPO}_{4}$-Coated $\mathrm{LiMn}_{2} \mathrm{O}_{4}$ for Lithium Ion Batteries. Materials Letters 2007, 61, 4703-4706.

(16) Dobbelaere, T.; Mattelaer, F.; Roy, A.; Vereecken, P.; Detavernier, C. PlasmaEnhanced Atomic Layer Deposition of Titanium Phosphate as an Electrode for Lithiumion Batteries. Journal of Materials Chemistry A 2017, 5, 330-338.

(17) Dobbelaere, T.; Mattelaer, F.; Dendooven, J.; Vereecken, P.; Detavernier, C. PlasmaEnhanced Atomic Layer Deposition of Iron Phosphate as a Positive Electrode for 3D Lithium-Ion Microbatteries. Chemistry of Materials 2016, 28, 3435-3445.

(18) Eftekhari, A. $\mathrm{LiFePO}_{4} / \mathrm{C}$ Nanocomposites for Lithium-ion Batteries. Journal of Power Sources 2017, 343, 395-411.

(19) Cho, J.; Kim, T.; Kim, C.; Lee, J.; Kim, Y.; Park, B. Comparison of $\mathrm{Al}_{2} \mathrm{O}_{3^{-}}$and $\mathrm{AlPO}_{4}$-coated $\mathrm{LiCoO}_{2}$ Cathode Materials for a Li-ion Cell. Journal of Power Sources 2005, 146, 58-64.

(20) Deng, S.; Verbruggen, S.; Lenaerts, S.; Martens, J.; Van den Berghe, S.; Devloo-Casier, K.; Devulder, W.; Dendooven, J.; Deduytsche, D.; Detavernier, C. Controllable Nitrogen Doping in As Deposited $\mathrm{TiO}_{2}$ Film and its Effect on Post Deposition Annealing. Journal of Vacuum Science \& Technology A: Vacuum, Surfaces, and Films 2014, 32, 01A123.

(21) Kozen, A.; Pearse, A.; Lin, C.; Noked, M.; Rubloff, G.Atomic Layer Deposition of the Solid Electrolyte LiPON. Chemistry of Materials 2015, 27, 5324-5331.

(22) Munoz, F.; Duran, A.; Pascual, L.; Montagne, L.; Revel, B.; Rodrigues, A. Increased Electrical Conductivity of LiPON Glasses Produced by Ammonolysis. Solid State Ionics 2008, 179, 574-579.

(23) Johnson, R.; Hultqvist, A.; Bent, S. A Brief Review of Atomic Layer Deposition: from fundamentals to applications. Materials Today 2014, 17, 236-246. 
(24) Dobbelaere, T.; Roy, A.; Vereecken, P.; Detavernier, C. Atomic Layer Deposition of Aluminum Phosphate Based on the Plasma Polymerization of Trimethyl Phosphate. Chemistry of Materials 2014, 26, 6863-6871.

(25) Dobbelaere, T.; Mattelaer, F.; Vereecken, P.; Detavernier, C. Plasma-enhanced Atomic Layer Deposition of Vanadium Phosphate as a Lithium-ion Battery Electrode Material. Journal of Vacuum Science \& Technology A: Vacuum, Surfaces, and Films 2017, 35, 041513.

(26) Dobbelaere, T.; Minjauw, M.; Ahmad, T.; Vereecken, P.; Detavernier, C. Plasmaenhanced Atomic Layer Deposition of Zinc Phosphate. Journal of Non-Crystalline Solids 2016, 444, 43-48.

(27) Rongé, J.; Dobbelaere, T.; Henderick, L.; Minjauw, M.; Sree, S.; Dendooven, J.; Martens, J.; Detavernier, C.Bifunctional Earth-abundant Phosphate/Phosphide Catalysts Prepared Via Atomic Layer Deposition for Electrocatalytic Water Splitting. Nanoscale Advances 2019, 1, 4166-4172.

(28) Nisula, M.; Shindo, Y.; Koga, H.; Karppinen, M. Atomic Layer Deposition of Lithium Phosphorus Oxynitride. Chemistry of Materials 2015, 27, 6987-6993.

(29) Meersschaut, J.; Vandervorst, W. High-throughput Ion Beam Analysis at imec. Nuclear Instruments and Methods in Physics Research Section B: Beam Interactions with Materials and Atoms 2017, 406, 25-29.

(30) Dobbelaere, T.; Vereecken, P.; Detavernier, C. A USB-controlled Potentiostat/Galvanostat for Thin-film Battery Characterization. HardwareX 2017, 2, 34-49.

(31) Wolf, J.; Etter, R.; Schaer, M.; Siegenthaler, P.; Zenobi, R.Direct and Sensitive Detection of CWA Simulants by Active Capillary Plasma Ionization Coupled to a Handheld Ion Trap Mass Spectrometer. Journal of The American Society for Mass Spectrometry 2016, 27, 1197-1202. 
(32) Pearse, A.; Schmitt, T.; Fuller, E.; El-Gabaly, F.; Lin, C.; Gerasopoulos, K.; Kozen, A.; Talin, A.; Rubloff, G.; Gregorczyk, K. Nanoscale Solid State Batteries Enabled by Thermal Atomic Layer Deposition of a Lithium Polyphosphazene Solid State Electrolyte. Chemistry of Materials 2017, 29, 3740-3753.

(33) Mascaraque, N.; Fierro, J.; Durán, A.; Muñoz, F. An Interpretation for the Increase of Ionic Conductivity by Nitrogen Incorporation in LiPON Oxynitride Glasses. Solid State Ionics 2013, 233, 73-79.

(34) Zahedi-Niaki, M.; Joshi, P.; Kaliaguine, S. Synthesis and Characterization of AlPO-36, the Missing End-member of ATS Structure. Chemical Communications 1996, 1373.

(35) Vereecke, G.; Rouxhet, P. Surface Charging of Insulating Samples in X-ray Photoelectron Spectroscopy. Surface and Interface Analysis 1998, 26, 490-497.

(36) Han, S.; Smith, J.; Pluth, J.; Richardson, J. Crystal Structure of MAPO-20 Sodalite: Theoretical Analysis of Three-color Ordering of $\mathrm{Mg}, \mathrm{Al}$ and $\mathrm{P}$ in a Sodalite Unit. European Journal of Mineralogy 1990, 2, 787-798.

(37) Mascaraque, N.; Fierro, J.; Durán, A.; Muñoz, F. An Interpretation for the Increase of Ionic Conductivity by Nitrogen Incorporation in LiPON Oxynitride Glasses. Solid State Ionics 2013, 233, 73-79.

(38) Atosuo, E.; Mäntymäki, M.; Mizohata, K.; Heikkilä, M.; Räisänen, J.; Ritala, M.; Leskelä, M. Preparation of Lithium Containing Oxides by the Solid State Reaction of Atomic Layer Deposited Thin Films. Chemistry of Materials 2017, 29, 998-1005.

(39) Bard, A.; Faulkner, L. Electrochemical Methods and Applications; Wiley-Interscience: New York, 2000. 


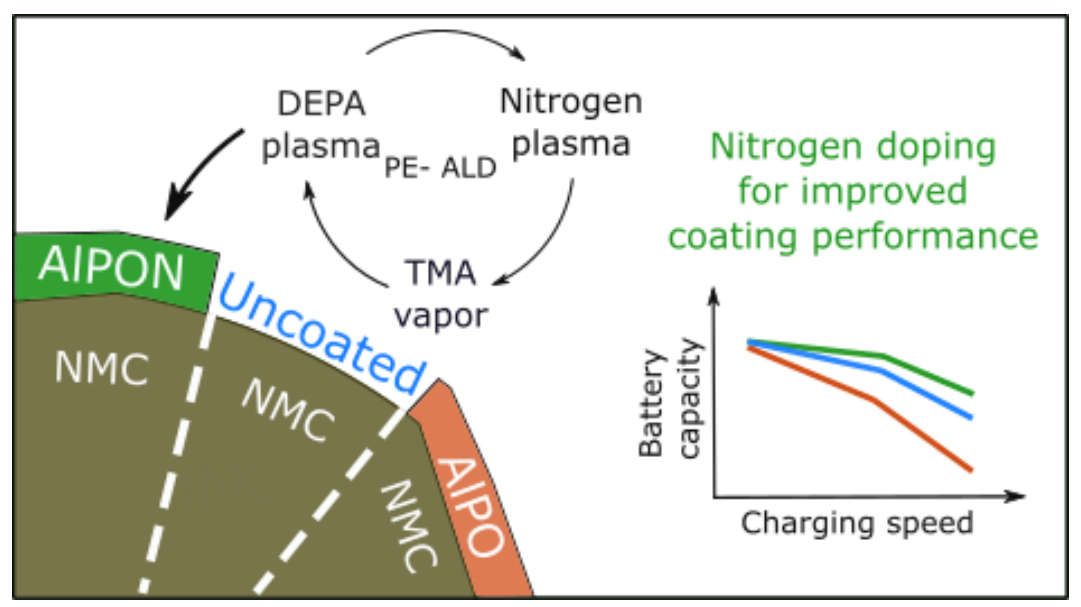

